\title{
Testing the ability of the ExoMars 2018 payload to document geological context and potential habitability on Mars
}

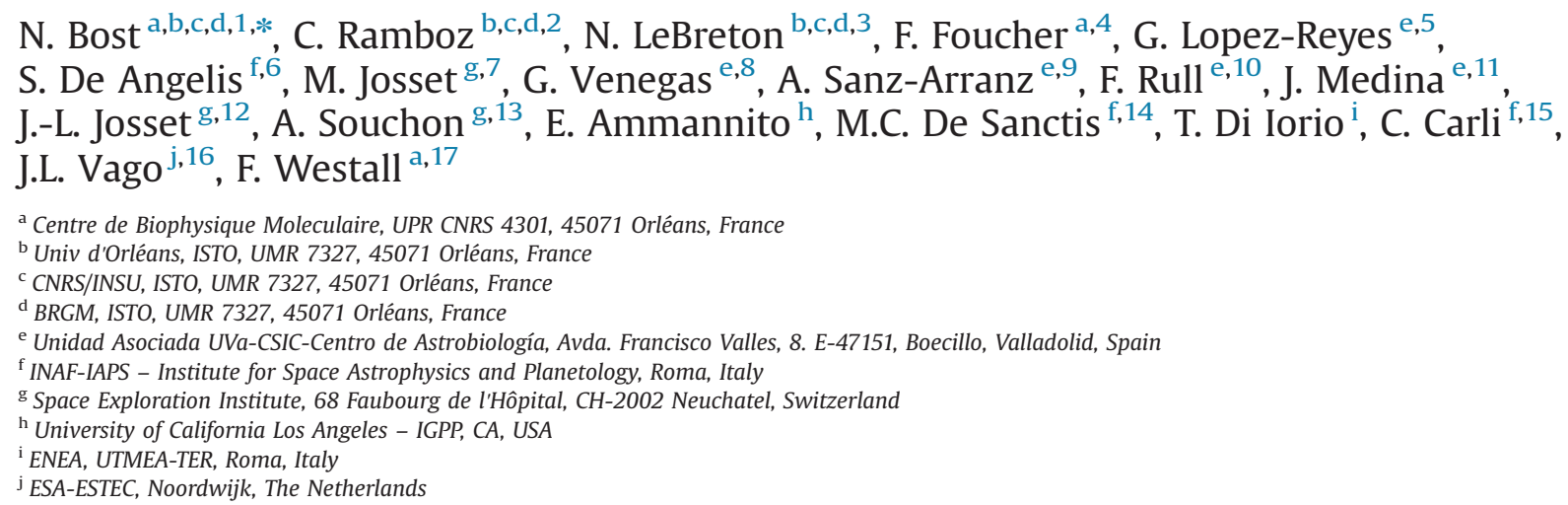

\section{A R T I C L E I N F O}

Article history:

Received 24 July 2014

Received in revised form

18 December 2014

Accepted 12 January 2015

Available online 30 January 2015

Keywords:

ExoMars

Mars

ISAR

\begin{abstract}
A B S T R A C T
The future ExoMars rover mission (ESA/Roscosmos), to be launched in 2018, will investigate the habitability of the Martian surface and near subsurface, and search for traces of past life in the form of textural biosignatures and organic molecules. In support of this mission, a selection of relevant Mars analogue materials has been characterised and stored in the International Space Analogue Rockstore (ISAR), hosted in Orléans, France. Two ISAR samples were analysed by prototypes of the ExoMars rover instruments used for petrographic study. The objective was to determine whether a full interpretation of the rocks could be achieved on the basis of the data obtained by the ExoMars visible-IR imager and spectrometer (MicrOmega), the close-up imager (CLUPI), the drill infrared spectrometer (Ma_Miss) and the Raman spectrometer (RLS), first separately then in their entirety. In order to not influence the initial instrumental interpretation, the samples were sent to the different teams without any additional
\end{abstract}

\footnotetext{
* Corresponding author at: Centre de Biophysique Moleculaire, UPR CNRS 4301, 45071 Orléans, France. Tel.: +33 (0)2 38255576

E-mail addresses: bost.nicolas@orange.fr, nicolas.bost@cnrs-orleans.fr (N. Bost), claire.ramboz@cnrs-orleans.fr (C. Ramboz), nicole.le-breton@univ-orleans.fr (N. LeBreton), frederic.foucher@cnrs-orleans.fr (F. Foucher), guillermo.lopez.reyes@cab.inta-csic.es (G. Lopez-Reyes), Simone.deangelis@iaps.inaf.it (S. De Angelis), marie.josset@space-X.ch (M. Josset), venegasdvg@cab.inta-csic.es (G. Venegas), jausanz@fmc.uva.es (A. Sanz-Arranz), rull@fmc.uva.es (F. Rull), medina@fmc.uva.es (J. Medina), jean-luc.josset@space-X.ch (J.-L. Josset), audrey.souchon@space-X.ch (A. Souchon), eleonora.ammannito@iaps.inaf.it (E. Ammannito), mariacristina.desanctis@iaps.inaf.it (M.C. De Sanctis), tatiana.diiorio@iaps.inaf.it (T. Di Iorio),

Cristian.carli@iaps.inaf.it (C. Carli), Jorge.Vago@esa.int (J.L. Vago), frances.westall@cnrs-orleans.fr (F. Westall).

${ }^{1}$ Present adress: CEMHTI, UPR3079, 45071 Orléans, France.

2 Tel.: + 33238255245 .

${ }^{3}$ Tel.: + 33238494654 .

${ }^{4}$ Tel.: +33238257641

${ }^{5}$ Tel.: + 34983140505 .

${ }^{6}$ Tel.: +390649934083 .

7 Tel.: +41328896869

${ }^{8}$ Tel.: + 34983140500 .

${ }^{9}$ Tel.: +34983140500.

${ }^{10}$ Tel.: + 34983423195 .

${ }^{11}$ Tel.: + 34983423190 .

${ }^{12}$ Tel.: +41328896869.

${ }^{13}$ Tel.: +41328896869.

${ }^{14}$ Tel.: + 3906499934444

15 Tel.: + 390649934096 .

${ }^{16}$ Tel.: + 31715655211 .

${ }^{17}$ Tel.: + 33238257912 .
} 
VNIR and Raman Spectroscopy, MicrOmega, Ma_Miss and RLS

Geology information. This first step was called the "Blind Test" phase. The data obtained by the instruments were then complemented with photography of the relevant outcrops (as would be available during the ExoMars mission) before being presented to two geologists tasked with the interpretation. The context data and photography of the outcrops and of the samples were sufficient for the geologists to identify the rocks. This initial identification was crucial for the subsequent, iterative interpretation of the spectroscopic data. The data from the different spectrometers was, thus, cross-calibrated against the photographic interpretations and against each other. In this way, important mineralogical details, such as evidence of aqueous alteration of the rocks, provided relevant information concerning potential habitable conditions. The final conclusion from this test is that, when processed together, the ExoMars payload instruments produce complementary data allowing reliable interpretation of the geological context and potential for habitable environments. This background information is fundamental for the analysis and interpretation of organics in the processed Martian rocks.

(c) 2015 Elsevier Ltd. All rights reserved.

\section{Introduction}

The ExoMars rover mission (ESA/Roscosmos) will be launched in 2018 (ESA, 2013). The science objectives of the mission are as follows: (1) to investigate the habitability of the landing site; (2) to determine whether the materials present are compatible with the preservation of potential traces of life; and (3) to search for traces of past or present life, including prebiotic and abiotic organics (ESA, 2013). To achieve these objectives, the mission will have to investigate the geological diversity of rocks at the landing site. The ExoMars rover consists of a suite of complementary instruments for observation and analysis. A panoramic camera PanCam and the close-up imager CLUPI will be used to obtain context, structural, and textural information from the kilometre- to the sub-millimetre-scale, while the ISEM (long range infrared spectrometer), mounted on the mast, will determine the target soil/rock bulk mineralogical composition. A drill will obtain samples down to two metres depth. The drill is equipped with an IR spectrometer "Mars Multispectral Imager for Subsurface Studies" (Ma_Miss; Coradini et al., 2001) for determining down hole mineralogy (Fig. 1). The samples will be delivered to the internal laboratory where they will be crushed. The mineralogy will be investigated with the visual and infrared (IR) imaging spectrometer MicrOmega and the Raman Laser Spectrometer (RLS), which can also detect the presence of organic matter. More detailed investigation of the organics will be made by the instrument Mars Organic Molecule
Analyser (MOMA), consisting of laser desorption mass spectrometer (LDMS) and (gas chromatograph mass spectrometery).

In support of this mission, Bost et al. (2013) developed a collection of Mars analogue rocks and minerals collectively known as the International Space Analogue Rockstore (ISAR, www.isar. cnrs-orleans.fr), stored at the CNRS in Orléans, France. ISAR contains well-characterised samples (sedimentary, volcanic and magmatic in origin) available for testing and calibrating space instruments. Currently, several teams use this collection to obtain scientific reference data on minerals and rocks.

However, to date, there has been no comprehensive test of the ExoMars geological suite of instruments using representative Mars analogue samples. Such studies are essential for adequately preparing future in situ investigations and to develop protocols based on the cross-correlation of the data. In this contribution, we describe a test of the ExoMars geological instrument suite consisting of two phases. In the first phase, called the "Blind Test", the ExoMars instrument teams CLUPI, Ma_Miss, MicrOmega, and RLS were requested by the ISAR group to perform mission representative measurements on two rocks selected from the ISAR collection. They were given small sample aliquots without additional context information and without data from the other instruments. For interpretation, each instrument team could only rely on its own measurements. In the second phase, the complete set of ExoMars instrument results, together with aerial images - comparable to

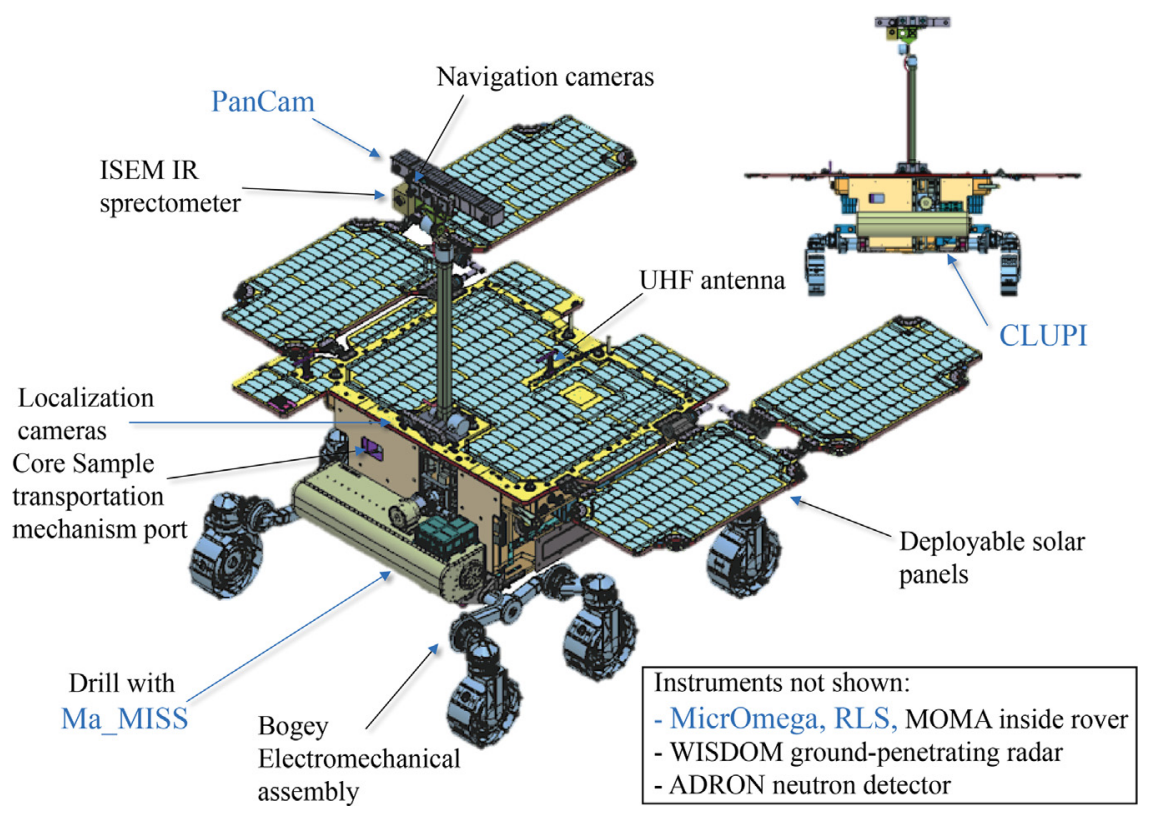

Fig. 1. Sketch of the ExoMars rover and the instruments locations. Credit: ESA. 
Mars orbital images - and photographs of the outcrops from which the samples had been obtained in the field - mimicking PanCam photographs - were submitted to geologists having no previous knowledge of the rocks used in this exercise. The aim was, first, to identify the rocks, then the information from each instrument was cross-correlated in order to re-evaluate the initial interpretation. Finally, the cross-calibrated data were used to fully characterise the samples, not simply in terms of rock type, but also for any features, such as alteration in the presence of water, that could provide information on potential habitability.

\section{Methodology used for the Blind Test}

This Blind Test was designed to address the geological capabilities of the ExoMars payload, so a procedure similar to that defined for the ExoMars mission was used.

\subsection{Sample selection and characterisation during the ExoMars mission}

The characterisation of rocks and the selection of samples during the ExoMars rover mission will be made using a specific protocol. The panoramic instruments, including PanCam (including wide-angle and high resolution cameras) and ISEM, will scan and analyse the panorama and identify potentially interesting targets. This information will be employed to decide which target to approach for further investigation. PanCam will be used to study outcrops, rocks, and soils, while detailed images of these materials will be made by the close-up imager CLUPI - accommodated on an external wall of the drill box - which has several viewing modes. CLUPI will observe rock textures in macroscopic mode to understand their nature and characterise potentially visible morphological biosignatures. The synergetic combination of PanCam and CLUPI will provide powerful, nested imaging capabilities from the panoramic to the submillimetric scale. This data is important for interpretation of rock type, mode of formation, and habitability potential, as well as for identifying lithologies that could potentially preserve traces of past life.

Samples will be collected with a drill tool hosting the Ma_Miss instrument (Fig. 1). Ma_Miss can perform spectral measurements to identify subsurface minerals as the drill moves in the borehole. PanCam and CLUPI will also be used to study the powdered fines produced during drilling, as well as the samples collected by the dril at high resolution, prior to their delivery to the analytical laboratory.

Once a sample has reached the analytical laboratory, it is crushed by the Sample Preparation and Distribution System (SPDS) to a particle size of approximately $250 \mu \mathrm{m}$ and delivered to a carousel for IR and Raman spectrometry (MicrOmega and RLS) investigations and for analysis using the Mars Organic Molecule Analyser (MOMA) laser desorption mass spectrometry (LDMS) and gas chromatograph mass spectrometer (GCMS).

The test described here was designed to address the geological capabilities of the ExoMars payload and not the organic analyses that form part of a separate study. Furthermore, the PanCam and ISEM systems were not used because the test concentrated on the in situ measurements, although field photographs obtained with a commercial camera served as substitute PanCam data.

\subsection{Sample selection and preparation for the Blind Test}

Two samples from the ISAR collection were chosen for their analogy with Martian rocks and their pertinence for astrobiology. These samples, labelled "sample A" and "sample B", were previously fully characterised in the laboratory using XRD, Raman spectroscopy, IR spectroscopy, optical microscopy, Scanning
Electron Microscopy (SEM) and Electron Microprobe (EMP) in the framework of the ISAR project (Bost et al., 2013). Powdered samples with a grain size of $\sim 250 \mu \mathrm{m}$, similar to those provided by the rock crusher in the ExoMars SPDS (Lopez-Reyes et al., 2012; Foucher et al., 2013), were sent to the RLS and MicrOmega teams, without any images of the original samples. Both samples were sent as hand specimens to the CLUPI team, and as small slabs and powders to the Ma_Miss team. The teams only knew that the samples were representative of Martian rocks and that they could potentially contain biosignatures. It is important to note that, when the Blind Test phase was carried out (it started on 01/2012), these samples and the associated data were not available on the ISAR website and the related publication (Bost et al., 2013, submitted on 11/2012) had not yet been published. Consequently, neither the instruments teams nor the geologists had access to information related to the samples before this exercise.

\section{ExoMars instruments used for the Blind Test}

\subsection{Close-UP Imager (CLUPI)}

The CLUPI (Close-Up Imager) is an instrument developed by the Space Exploration Institute (Space-X) in Neuchatel, Switzerland. It is a miniaturised, low-mass, low-power, efficient and highly adaptive imaging system, composed of a colour image sensor $(2652 \times 1768 \times$ 3 pixels), an optics with focus mechanism and processing electronic boards. The camera is capable of focusing on any target at distances from $10 \mathrm{~cm}$ to infinity. The functionality of $z$-stacking is also implemented in order to increase the scientific return.

CLUPI is positioned on the rover's drill box and replaces the geologist's hand lens. It is scientific objectives during the ExoMars mission are: (1) geological environment survey: determination and characterisation of surface and rock types present in the immediate surroundings of the rover, study of the physical properties of the surface (e.g. compaction state) by inspection of the rover tracks, contribution to the selection of sites for detailed investigations (drilling); (2) close-up outcrop observation: study at high resolution (down to $7 \mu \mathrm{m} /$ pixels at $10 \mathrm{~cm}$ distance) of the texture, structure, and morphology of outcrops, surface rocks and particles, as well as potential biofabrics, colour variations and possible layering; (3) drilling area observation: characterisation of site before drilling; (4) drilling operation observation: to provide information about the ejected fines as they are produced, potential colour changes indicative of geological variation with depth, and the mechanical behaviour of the drilled surface in contact with the drill tip; (5) drilled core sample observation: to allow comparison of the extracted sample with the sampling area and visual examination of the texture and physical properties of the particles; and (6) drill hole observation: provide information on the surface state after drilling, the amount of ejected fines, their colour, and their physical properties.

The two Blind Test samples were imaged using a CLUPI analogue camera (Sigma SD15) with the same colour image sensor as the real CLUPI (but $20^{\circ}$ field of view optics instead of real CLUPI's $14^{\circ} \mathrm{FoV}$ ). The samples were deposited on a Martian surface analogue composed of Permian redbeds (red sandstones from Weitenau, southern Germany), and illuminated with a Sun simulator (Fig. 2a). Images of each sample were acquired from two rover-representative working distances, $54 \mathrm{~cm}$ (real CLUPI equivalent $76 \mathrm{~cm}$ ) and $25 \mathrm{~cm}$ (real CLUPI equivalent $35 \mathrm{~cm}$ ), with a pixel resolution of $60 \mu \mathrm{m}$ and $28 \mu \mathrm{m}$, respectively.

\subsection{Mars Multispectral Imager For Subsurface Studies (Ma_Miss)}

The Mars Multispectral Imager for Subsurface Studies (Ma_Miss) is developed by the Institute for Space Astrophysics and Planetology in 

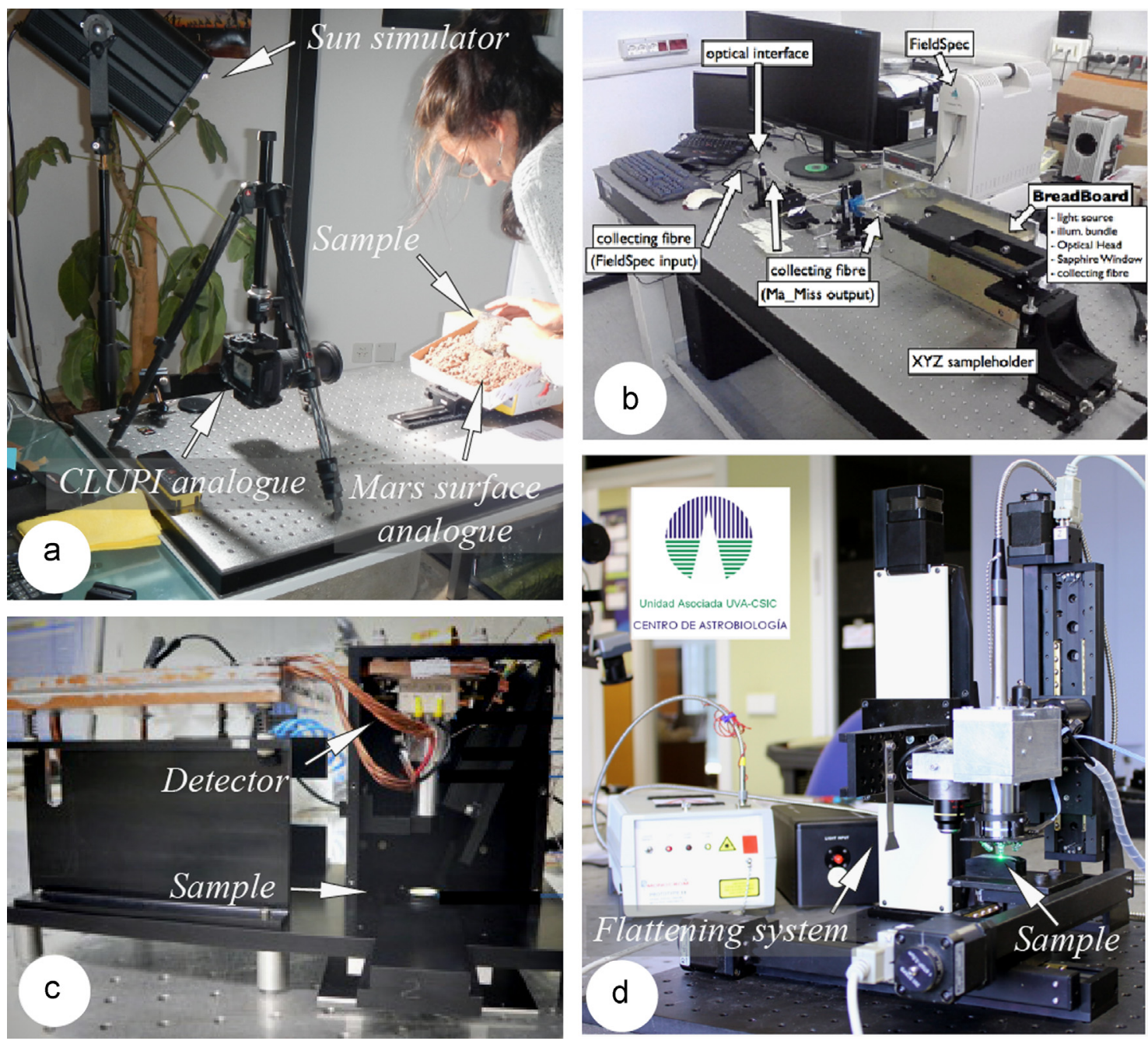

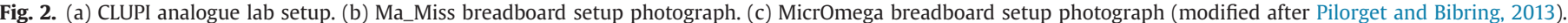
(d) RLS ExoMars simulator.

Rome, Italy (Coradini et al., 2001). Ma_Miss is a miniaturised nearinfrared imaging spectrometer in the range $0.4-2.2 \mu \mathrm{m}$ with $20-\mathrm{nm}$ spectral sampling. It is positioned in the drill tool a few centimeters above the drill tip, where a sapphire window (characterised by high transparence and hardness) protects the Ma_Miss optical head, permitting observation of the borehole wall.

The Ma_Miss optical head performs the double task of illuminating the borehole wall with a spot of approximately 1-mm diameter and, collecting the scattered light coming from a $0.1-\mathrm{mm}$ diameter region of the target, Ma_Miss can acquire spectral data from the walls of the drilled borehole. It is also capable of making spectral images of the borehole by using the drill rotation and translation movements. This instrument can obtain downhole images of the excavated borehole wall, performing acquisitions at different depths during vertical translation - in principle, from 0 to $2-m$ depth. Ma_Miss can also create so-called ring images, performing acquisitions during rotation of the drill at a fixed depth. The Ma_Miss breadboard used for this test consists of the following subsystems: a $5 \mathrm{~W}$ illumination lamp, an optical fibre illumination bundle, an optical head that focuses the light the sample and recollects the scattered light, a sapphire window (interface between optical head and the environment) and a collecting optical fibre (Fig. 2b).

The Blind Test samples were analysed using a preliminary version of the breadboard setup, interfaced with a commercial FieldSpec spectrophotometer. Reflectance spectra were acquired in the spectral range $0.35-1.8 \mu \mathrm{m}$. The sample slabs were placed directly on the sample holder. The plane surface (cut rock surface, representative of an abraded rock surface and the external surface of the drill-hole) was oriented perpendicularly to the optical axis of the spectrometer. Several spectra were acquired in different positions on the samples, simulating the Ma_Miss stratigraphic column acquisitions.

\subsection{MicrOmega}

MicrOmega consists of a visible light microscope and a near infrared imaging spectrometer (Pilorget, 2012; Pilorget and Bibring, 2013) (Fig. 2c). The instrument acquires monochromatic images with a high resolution of $20 \mu \mathrm{m} \times 20 \mu \mathrm{m}$ per pixel at wavelengths between $0.5 \mu \mathrm{m}$ and $0.9 \mu \mathrm{m}$ and with a continuous and high spectral sampling from $0.9 \mu \mathrm{m}$ to $2.5 \mu \mathrm{m}$ (now up to $3.5 \mu \mathrm{m}$ ). In this way MicrOmega acquires the entire spectrum in a spectral domain for each pixel, thus enabling it to identify the composition of the samples at their grain scale.

The Blind Test samples powders were analysed using the MicrOmega breadboard. In situ reflectance hyperspectral spectra were acquired on samples $7.4 \times 5.9 \mathrm{~mm}^{2}$ in size with a spatial sampling of $23 \mu \mathrm{m}$. The samples were illuminated by a monochromator with an Acousto Optical Tunable Filter (AOTF) in the range of $0.9-2.5 \mu \mathrm{m}$, oriented about $20^{\circ}$ with respect to the sample surface. The $320 \times 256$ pixel-infrared detector $($ MCT Mars SW1 
(Sofradir)) is sensitive in the $0.85-2.5 \mu \mathrm{m}$ spectral region. The focal plane was cooled down to $190{ }^{\circ} \mathrm{K}$.

\subsection{Raman Laser Spectrometer (RLS)}

The Raman Laser Spectrometer (RLS) is developed at the Associated Unit of the University of Valladolid-CSIC-Centre of Astrobiology (UVa-CAB), in Spain (Rull et al., 2011a, 2011b). The RLS is accommodated in the ExoMars rover's Analytical Laboratory Drawer (ALD). In automatic mode, the RLS can perform raster analysis of at least 20 points (and up to 40) of the powdered samples, using a $50-\mu \mathrm{m}$ spot size and an irradiance level of $0.6-1.2 \mathrm{~kW} / \mathrm{cm}^{2}$ with a $532 \mathrm{~nm}$ continuous wave, green laser.

The powdered Blind Test samples were analysed using an RLS ExoMars simulator that includes an SPDS in order to perform measurements under the operation conditions imposed by the rover-based operation (Fig. 2d; Lopez-Reyes et al., 2014; Rull et al., 2011a). This system provides automatic flattening of the powdered samples, autofocus at each measurement point, and optical images of the samples. In addition, the system autonomously optimises the acquisition parameters (integration time, number of accumulations, etc.) at each spot with the aid of appropriate algorithms (Lopez-Reyes et al., 2014). Thirty spots per sample were acquired in automatic mode. The spectra were pre-processed to remove the baseline and instrument artifacts. Mineral identification based on specific Raman lines was performed using the spectral database developed at the University of Valladolid (Hermosilla et al., 2012).

\section{Results of the Blind Test phase}

\subsection{Sample A}

\subsubsection{CLUPI}

CLUPI images were acquired on rough surfaces, as well as on a fresh cut face (simulating an abraded surface). Note that a similar system is not planned for the ExoMars rover mission. The external, uncleaned surface of the rock is characterised by alternating white and grey layers ranging from $\mathrm{mm}$ to $\mathrm{cm}$ in thickness. The surface of the rock appears to be a fracture surface and is coated with a whitish-orange-coloured alteration product (Fig. 4a-1 and a-2). The sharp angles observable on the fracture surface suggest that the rock is brittle. The cleaned surface of the rock provides a better view of the layering (Fig. 3a-3 and a-4). The layers are generally parallel to each other although the basal layer exhibits gentlyinclined internal laminae and its surface of the latter layer includes some $0.5-1 \mathrm{~cm}$-sized, rounded protrusions having a whitish cortex and a clear, orange-coloured internal component. The laminated nature of the rock suggests a sedimentary origin and the protuberances on the surface of the lower layer may be either mineral precipitations or detrital inclusions.

\subsubsection{Ma_Miss}

Spectral images of the cut rock surface were collected using the Ma_Miss breadboard and documented alternating dark and light albedo layers suggestive of a sedimentary rock. Several different spots were acquired on the sample, both on the dark and bright layers, simulating the stratigraphic column of the borehole. Also the powder was measured. The dark and bright layers of the slab have corresponding spectra with very similar shapes and absorption features, although they show different levels of reflectance and spectral contrast.

The spectra acquired on both samples (slab and powder) are characterised by the $\mathrm{OH}^{-}$absorption at $1.4 \mu \mathrm{m}$ (Fig.3b), indicating the presence of a water-containing mineral. On the slab, the $1.4-\mu \mathrm{m}$ band is larger and deeper for the high albedo layers than for the dark layers. This could be due to real differences in the $\mathrm{H}_{2} \mathrm{O}$ or $\mathrm{OH}$ content, or just due to a reduced spectral contrast on the darker region (Fig.3b). A strong negative slope characterises the spectra acquired in the bright region; the spectra of the dark layers show a smaller blue slope. Spectra of both layers show a clear crystal field (C.F.) absorption at $1 \mu \mathrm{m}$, whose wings extend beyond $1.2 \mu \mathrm{m}$, likely due to $\mathrm{Fe}^{2+}$ absorption (Burns, 1993; Hunt, 1977; Gaffey, 1985). The interpretation of this $1-\mu \mathrm{m}$. The interpretation of this $1-\mu \mathrm{m}$ absorption is not unambiguous because the iron responsible of the absorption could be present in silicates, oxides, sulfides, or carbonates. The succession of bright and dark spectra with very similar spectral shapes is also suggestive of a layered (sedimentary) structure.

\subsubsection{MicrOmega}

The IR spectrum (Fig.3c) obtained with the MicrOmega breadboard on the sample A powder shows absorption features at $1.4 \mu \mathrm{m}$ and $2.2 \mu \mathrm{m}$. There is also a very weak absorption feature at $1.9 \mu \mathrm{m}$. These features reflect the presence of $\mathrm{H}_{2} \mathrm{O}$ and $\mathrm{OH}^{-}$in the minerals with which they are associated. The preliminary identification is a match with the spectrum of kaolinite, a group of white clays (Fe-poor) containing aluminium.

\subsection{4. $R L S$}

The thirty Raman spectra acquired on the sample powder permit identification of quartz, anatase, calcite, muscovite and disordered carbonaceous matter (Fig. 3d). The main rock-forming mineral is quartz.

\subsection{Sample $B$}

\subsubsection{CLUPI}

CLUPI photographed the rough and cut surfaces of Sample B. The rough surface is brownish in color and characterised by a criss-cross network of indentations (Fig. 4a-1 and a-2). The cut surface shows that the criss-cross network, resembling buff-coloured acicular structures, infilled veins, cracks, or crystals, continues into the rock (Fig. 5a-3 and a-4). The brown surface colour and buff-coloured acicular structures are restricted to the outer portion of the rock, which contrasts with the uniformly grey colour of the internal portion of the rock in which the acicular texture is still faintly visible. This contrast indicates significant weathering of the outer part of the rock.

\subsubsection{Ma_Miss}

Both the rough and freshly cut sample surfaces were observed. As in the previous sample, acquisition of Ma_Miss spectra at various points on the slabbed sample simulates the acquisition of data "downhole" in the drill column. Spectra were obtained both in the "bright region" (where the buff-coloured acicular structures occur) and in the "dark (grey) region" on the flat, cut rock surface (Fig.4b). The two regions are characterised by the presence of $\mathrm{OH}$; the $1.4-\mu \mathrm{m}$ band in the bright region spectra is larger and deeper than the corresponding band in the dark region. The spectrum of the dark region appears flat without evident absorption features. The bright region is characterised by a deep absorption near $1.0 \mu \mathrm{m}$, due to $\mathrm{Fe}^{2+}$ (Burns, 1993) and by an absorption at $0.7 \mu \mathrm{m}$, likely due to $\mathrm{Fe}^{2+}-\mathrm{Fe}^{3+}$ intervalence charge transfer (IVCT, although electronic processes due to transition elements such as $\mathrm{Ni}, \mathrm{Co}, \mathrm{Cr}, \mathrm{Fe}, \mathrm{Mn}$, Ti can occur in certain minerals in this region of the spectrum (Burns, 1993).

The absorption bands of spectra taken in the bright region are suggestive of the presence of mafic silicates, iron oxides, and hydrates indicative of possibly extensively altered mafic or ultramafic rocks with a higher concentration of hydrated mineral 

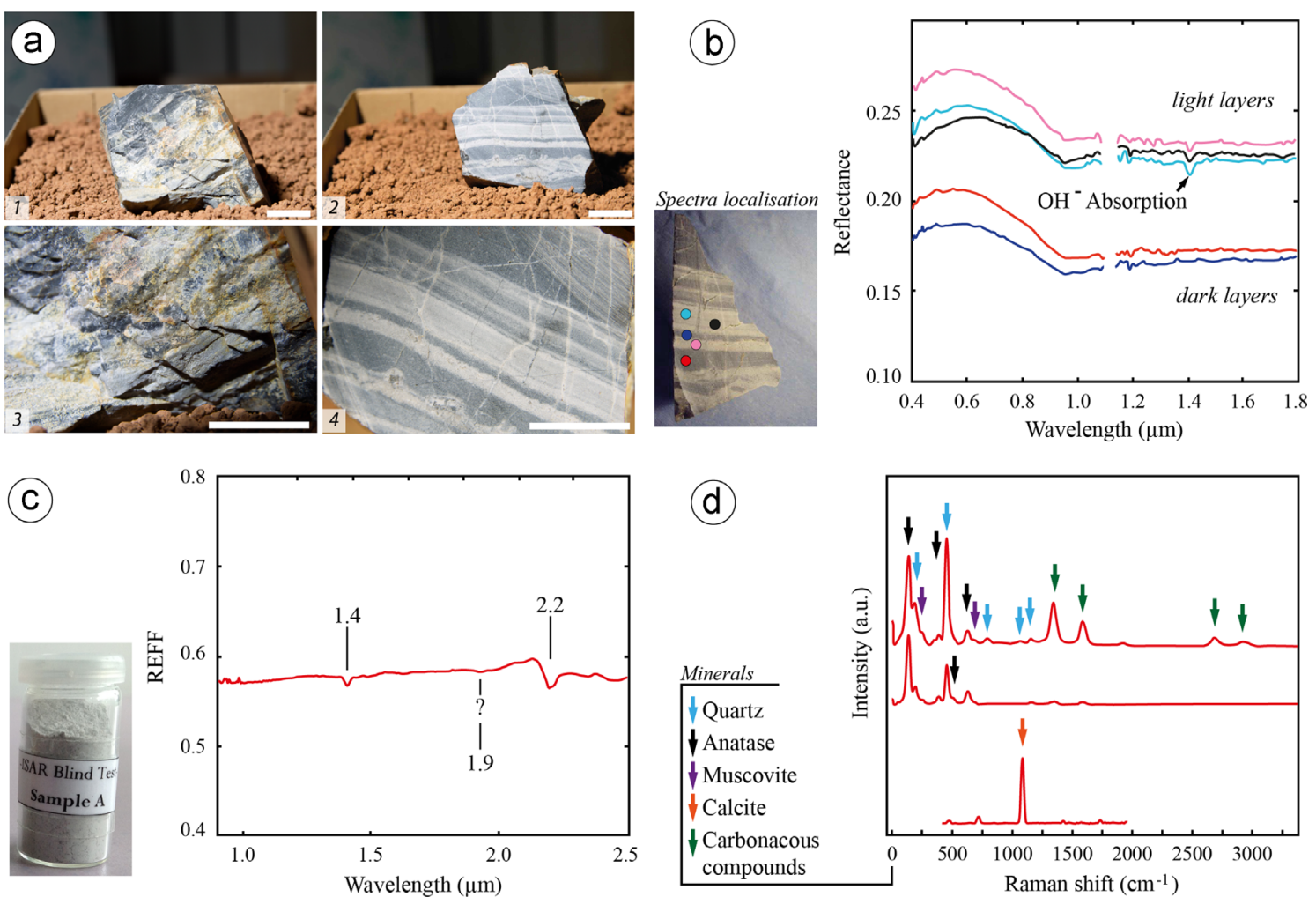

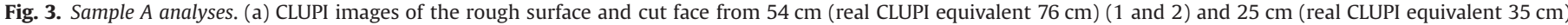

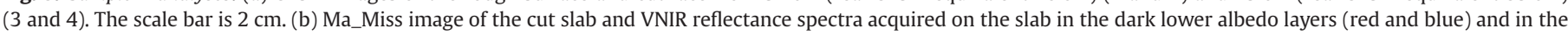

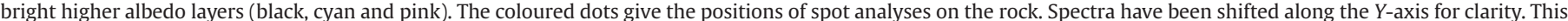

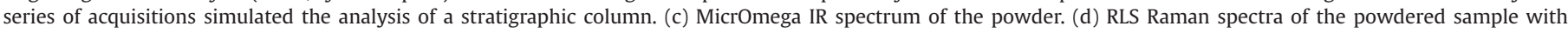
mineralogical assignation. (For interpretation of the references to colour in this figure legend, the reader is referred to the web version of this article.)
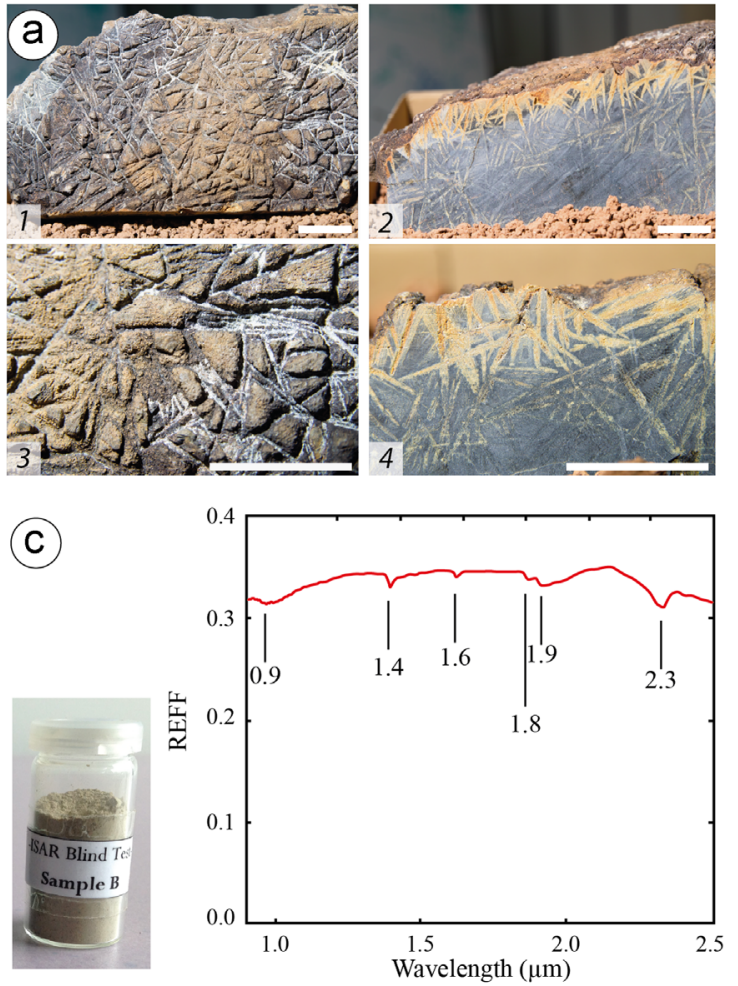

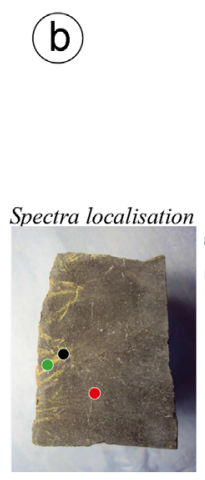

(d)

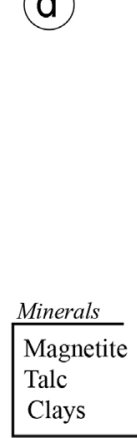

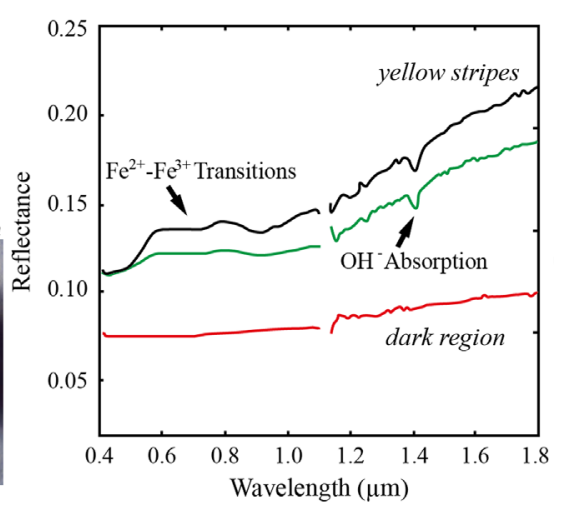

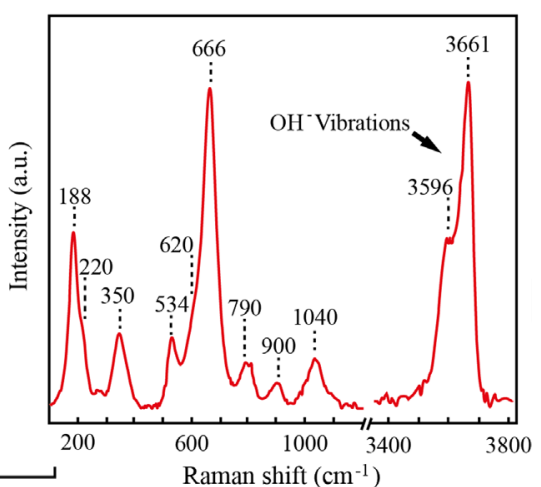

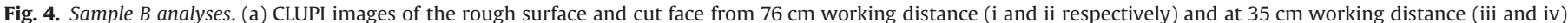

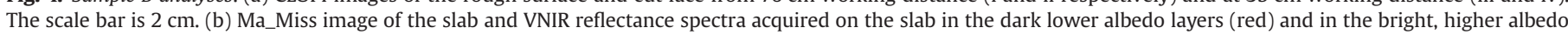

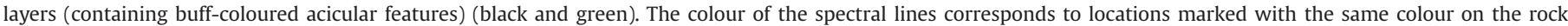

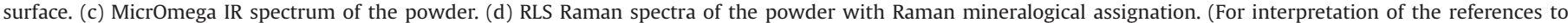
colour in this figure legend, the reader is referred to the web version of this article.) 

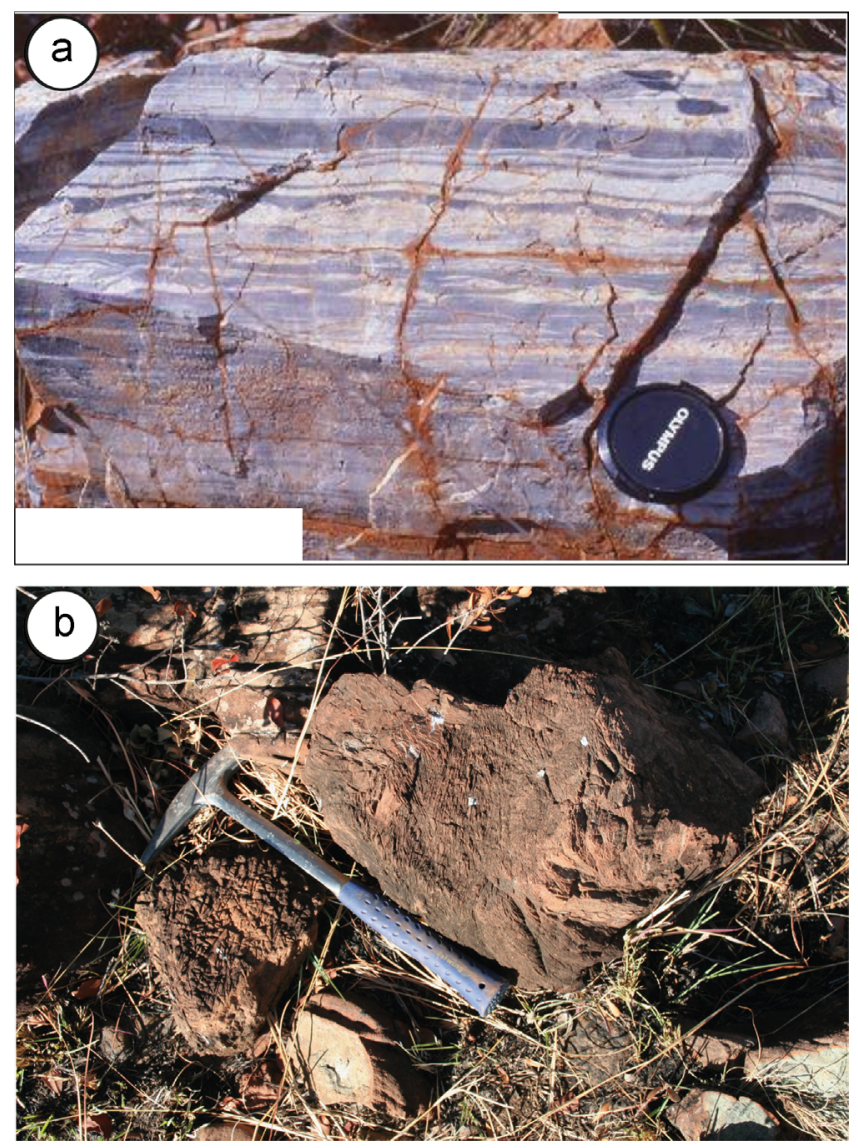

Fig. 5. Outcrop photographs of samples A and sample B (Figs. 5a and b, respectively).

phases in the brighter region (the water $\mathrm{OH}$ band suggests alteration of silicates). The spectrum acquired on powder substantially shows the same absorption bands as the rock sample, i.e. the iron electronic transitions at $0.7-1.0 \mu \mathrm{m}$, the $\mathrm{OH}$ absorption at $1.4 \mu \mathrm{m}$.

\subsubsection{MicrOmega}

The IR spectrum obtained from the powdered sample with the MicrOmega breadboard show absorption features at about 0.97 , $1.43,1.65,1.88,1.95$, and $23.3 \mu \mathrm{m}$. They are interpreted to reflect the presence of a mineralogical assemblage composed of saponite, serpentine and forsterite (the magnesium end-member of olivine) (Fig. 4c).

\subsubsection{RLS}

The Raman analysis of the powdered sample B provided generally fluorescent spectra with weak and very broad bands (Fig. 4d). This is consistent with a very low degree of crystallinity. The main bands can be assigned to a combination of magnetite and talc. Other small bands may also be assigned to clay minerals but more precise identification was not possible. Brucite is not compatible with the observed spectra; antigorite and/or lizardite (serpentine minerals) have also low probability. The first is characterised by a strong band at $1041 \mathrm{~cm}^{-1}$ that is not observed, while the bands of the second occur at higher wavenumbers than observed. However, the presence of a chloritoid cannot be totally ruled out. In some cases, the main band at $668 \mathrm{~cm}^{-1}$ shows a shoulder near $600 \mathrm{~cm}^{-1}$ that is consistent with the symmetrical chain vibration of chloritoid.

\section{Results of the geological interpretation phase}

Two geologists specialised in geochemistry (C.R.) and petrology (N.L.B.) interpreted jointly the bulk observational and analytical data for each sample to identify the rock type. In order to use the same kind of data set as would be available during the future ExoMars rover mission outcrop images (Fig. 5) corresponding to PanCam images were provided to complement the CLUPI images and the Ma_Miss, MicrOmega and RLS spectra. Outcrops images were obtained using commercial cameras (Olympus E410 camera, with a 10.00 Megapixel resolution, for sample A and Olympus OM1 camera for sample B).

The data interpretation followed a typical strategy, starting with the geological context (here given by the satellite observation), following by the optical outcrop and sample observation (here PanCam and CLUPI images) and finishing with the compositional data (here given by the Ma_Miss, MicrOmega and RLS spectroscopic data). Although the identification of the analogue rocks based on the optical images is a routine matter for geologists, this study underlined the importance of obtaining a maximum of information by cross-correlating the data in order to improve and/or re-evaluate the interpretation made by each instrument separately.

\subsection{Data interpretation of sample A}

The outcrop images show that the rock is massive but highly layered (Fig. 5a). It is thoroughly crosscut by numerous fractures, which suggests that it is hard and brittle. The $\mathrm{mm}$ - to $\mathrm{cm}$-wide layers consist of alternating grey-white to dark blue-grey beds. The upper and lower boundaries of the beds are generally linear, sometimes wavy, and could be interpreted as sedimentary features. Some beds are irregular in thickness because of pinching (either due to tectonic boudinage or sedimentary features?). Some dark centimetric, rounded to angular features disrupts the bedding. The massive, competent aspect of the outcrop is compatible with siliceous beds (cherts or quartzites) or marbles (metamorphosed carbonate beds). Evaporites are doubtful, given the brittle character of the outcrop. The alternation of beds with different colours in an apparently homogeneously competent material may either be accounted for by different grain size in beds with similar composition, or by mineralogical differences. If the rocks are siliceous (i.e. chert), the darker beds could be finer grained (light would diffuse at grain boundaries), whereas the lighter levels could be coarser-grained. Another possibility is that the darker beds display films of carbonaceous matter at grain boundaries, or contain fine oxide or sulphide grains.

CLUPI and Ma_Miss observations confirm the sedimentary origin of the sample (Fig. $3 a$ and b). The grey-white amorphous layer in the lower part of the sample looks like silica gel, which would support the hypothesis of a chert. The lobated surface of some beds could be fine sedimentary structures that have been preserved as they were rapidly covered by the overlying sediment. Although the rock exhibits a massive appearance suggestive of chert, the clear $\mathrm{Fe}^{2+}$ absorption seen by Ma_Miss (and MicrOmega) at $1.0 \mu \mathrm{m}$ is typical of igneous rock silicates. This suggests that the rock was originally volcanic in nature. The low albedo of the dark region may then possibly be due to the presence of vitrified material (such as a glass). The dichotomy in albedo and spectral characteristics observed in the different spots indicate a stratified structure typical of sedimentary rocks. Moreover, the presence of $\mathrm{OH}$ absorptions suggests that the volcanic material making up the rock was altered in the presence of water.

The detection of kaolinite by MicrOmega (Fig. 3c) is very surprising and does not fit with the optical observations of the hard, brittle character of the outcropping rock. It is concluded that, 
if kaolinite is present in the sample, it is more likely a very minor phase than a major component of the sample.

The RLS data (Fig. 3d) are in more direct accordance with the optical data. In particular, the detection of quartz as a major constituent fits well with the previous interpretation of a chert rock type. The presence of carbonaceous matter is also consistent with the suggestion that the rock is of sedimentary origin, the carbonaceous compounds being more specifically associated with the darker layers. Since calcite is detected in only a few analyses, it is interpreted as only a minor rock component. The systematic detection of anatase and the small amounts of muscovite may indicate a detrital volcanic origin of the sediment in interaction with hydrothermal processes. Water was involved in the formation of this sediment. The Raman data help to eliminate the hypothesis of a banded. The kaolinite hypothesised by MicrOmega, the muscovite proposed by RLS, and the hydrated components identified by Ma_Miss can all be associated with dioctahedral smectites.

Finally, the interpretation that the rock is a banded chert with anatase (common in chert) and a small amount of dioctahedral mica is the most likely. The lighter beds are siliceous, whereas the darker ones could contain carbonaceous matter and/or anatase. Quartz is the main constituent as shown by Raman analyses. Note that quartz cannot be detected by IR spectroscopy in the spectral range used by MicrOmega and Ma_Miss. In order to explain the detection of kaolinite, which is not in accordance with a chert, the IR data interpretation was revised. It is concluded that the spectrum most probably corresponds to muscovite, in accordance with the Raman data and consistent with the fact that the spectra of kaolinite and muscovite are relatively similar in the $0.9-2.5 \mu \mathrm{m}$ spectral range.

\subsection{Data interpretation of sample $B$}

The surface of the rocks at the outcrop appears dark green to red, suggesting they are iron-rich and partly oxidised (Fig. 5b).

The outcrop photographs show that the rock is massive and characterised by what appear to be cracks. Its twisted structure evokes corodate basalt and in this regard, the rugged surface could correspond to a scoriaceous lava. The sample surface shows a reddish stain (patina?) which is compatible with lava. Such a patina could also characterize a peridotite (mantle rock) exposed to weathering. The white dots could be calcite or plagioclase.

The CLUPI optical observations confirm the red patina on the sample surface, which evokes a weathered volcanic rock. The acicular texture is characteristic of the spinifex texture of komatiites (Fig. 4a).

The Ma_Miss spectra are in accordance with the a volcanic origin of the rock (Fig. 4b), i.e. clear crystal field absorption due to $\mathrm{Fe}^{2+}$ at $1.0 \mu \mathrm{m}$ indicative of iron silicate-bearing phases of ultramafic/mafic rocks. Moreover, the $\mathrm{OH}^{-}$band suggests mineral alteration, indicative of possibly extensively altered mafic or ultramafic rocks, with higher a concentration of hydrated mineral phases in the brighter region (serpentine group minerals, olivine/ pyroxene alteration products, for example antigorite, see Clark et al., 1990). The spectral signals pointing to $\mathrm{Fe}^{2+}-\mathrm{Fe}^{3+}$ IVCT transitions at $0.7 \mu \mathrm{m}$ and to $\mathrm{Fe}^{2+}$ C.F. transition at $\sim 1.0 \mu \mathrm{m}$, together with the $\mathrm{OH}^{-}$absorption bands are quite consistent with the fact that such primitive mafic rocks are unstable in the present day oxidised and hydrated surface environment. Again, the dark colour of the sample is compatible with a volcanic rock (basalt) or a peridotite. The exposed surface of the sample has in its centre a massive, light-brown structure whose periphery has a brecciated structure (Fig. 5b). The light-brown central structure is surrounded by a dense network of dark linear structures, which could correspond to fractures or, more likely, to skeletal olivine crystals in exhibiting spinifex texture.
On the fresh cut surface, the rock appears dark and very massive. It is finely grained and probably basaltic in nature. White dots on the surface, seen also in the outcrop, could be either plagioclase or calcite. Yellowish greenish, narrow, specular phases occur in the upper part of the sample. Two interpretations can be proposed:

- The surface of the rock may represent a fracture plane along which the rock is altered. The yellow crystals would then result from the alteration of a mineral such as olivine along this plane.

- The structure on top of the rock represents magmatic layering. The yellow skeletal crystals are rooted on a planar surface perpendicular to the observed rock section (a magmatic floor) and grow perpendicularly or obliquely to this plane. This evokes skeletal crystal growth from a supercooled, layered magma of low viscosity. Given the probable basaltic nature of the sample, the yellow acicular crystals are probably olivine forming a spinifex texture.

The olivine, serpentine and saponite (a trioctahedral smectite) detected by IR spectroscopy are quite consistent with a mafic rock (e.g. an olivine-bearing basalt) that has been hydrothermally altered to serpentine and saponite (Fig. 4c).

In the final analysis, particular aspects, such as outcrop structure, the macroscopic aspect of the lava, and IR data, favour the interpretation of anolivine-bearing basalt. Additional features allow the rock to be characterised as ultramafic. These include primary magmatic features, such as the spinifex texture of a mineral identified as olivine, possible magmatic layering, and the $\mathrm{Mg}$ - and $\mathrm{Fe}^{2+}$-rich character of the rock. Moreover, the presence of serpentine with iron oxidation-related features on the surface of sample B demonstrates that the rock has been aqueously altered. However, some index minerals of mafic magmas, such as pyroxene and plagioclase, were not detected by spectroscopy, although the white dots visible on the rock surface could be plagioclase. Antigorite was detected in the Ma-Miss IR spectra and perhaps in the Raman spectrum. Magnetite was detected by Raman and is typically formed during serpentinization (alteration) of mafic rocks.

\section{Full characterisation of the samples}

In this section, we present the complementary analytical data obtained for the two samples in the framework of the ISAR collection using a large range of laboratory techniques and laboratory instrumentation. Detailed data are also available on the ISAR website: www.isar.cnrs-orleans.fr.

\subsection{Sample $A$}

Sample A is the sample 00AU05 of the ISAR collection (Bost et al., 2013). It is a silicified volcanic sediment (chert) from the 3.446 Gy-old Kitty's Gap Chert in the Panorama formation of the Warrawoona Group, Pilbara craton, Australia (de Vries, 2004; Westall et al., 2006). Although its main constituent is now microcrystalline quartz $\left(\mathrm{SiO}_{2}\right)$, optical microscopy of thin sections of the rock shows that it consists of volcanic clasts that have been altered to muscovite and anatase and then largely replaced by silica of seawater and hydrothermal origin (confirmed by $\mu$-Raman spectroscopy and mapping). Structures observable at outcrop scale (layering) and textures observable at the microscopic scale indicate that the rock represents volcanic sediments that were deposited in a very shallow marine environment; such as an infilling tidal channel (de Vries, 2004). The traces of carbonaceous matter identified by Raman are related to the presence of fossilised (silicified) microbial colonies (Westall et al., 2006; Westall et al., 2011). Concentrated on the surfaces of volcanic grains and in the 
pore spaces between the volcanic grains, these colonies most likely represent relatively simple microorganisms, such as chemolithotrophs that obtain their energy, nutrients and carbon from inorganic sources. This sample is, thus, particularly relevant in terms of the search for life on Mars since these volcanoclastic sediments were deposited in a shallow water aqueous environmental setting that would have been relatively common in the Noachian period on Mars. The simple, chemotrophic life forms that they contain could therefore hypothetically reflect the kinds of simple life that may have occurred on Noachian Mars (Westall et al., 2011; Westall et al., 2013). Moreover, during the Noachian, hydrothermal processes associated with impacts and volcanic activity were likely to have been important on Mars (e.g. Schwenzer and Kring, 2009), and the precipitation of silica and subsequent silicification of igneous and sedimentary rocks and any life forms that might be associated is therefore possible. Silica has only recently been detected on Mars (Bish et al., 2013; Blake et al., 2013), possibly due to technical limitations since quartz has no IR signal in the spectral range used for Martian exploration.

\subsection{Sample $B$}

Sample B is the sample 10ZA09 of the ISAR collection (Bost et al., 2013). It is a weathered komatiite from the type locality on the Komatii River in the Barberton Greenstone belt, in South Africa (Bost et al., 2013). The main constituents are olivine, antigorite, micas and clays, as well as traces of haematite, magnetite and talc. Some trace of carbon (carbonaceous matter) is also observed in this sample. Volcanic rocks, in particular basalts, are very common on the martian surface (e.g. McSween et al., 2009). Although, they are richer in Fe and $\mathrm{Mg}$ than present-day terrestrial volcanics, many volcanic rocks dating back to the Archaean epoch were also richer in $\mathrm{Fe}$ and $\mathrm{Mg}$, especially the komatiites. The possible presence of komatiite-like rocks from the Noachian epoch on Mars has been evoked by Nva-Mvondo and Martinez-Frias (2007). It is also interesting to note that a recent experiment to produce artificial basalts with a martian composition surprisingly created spinifex-like textures (Bost et al., 2012; Chevrel et al., 2014).

\section{Discussion and conclusions}

The results collected during the Blind Test are compared to the ISAR data in Table 1 . There are only a few differences between the analyses made by the Exomars breadboard instruments (and a CLUPI-like camera) and those made by standard laboratory instruments. For sample A, calcite was detected by the RLS while it was not observed during the characterisation made for the ISAR collection (although Orberger et al., (2006) previously detected traces of Ca-Mg-carbonates in this sample). This is due to the large area of analysis ( $50 \mu \mathrm{m}$ ) of the RLS compared to spot analyses made by laboratory instruments. On the other hand, goethite and rutile, present in the sample, were not detected by the ExoMars instruments. For sample B, the ExoMars instruments did not detect phlogopite, haematite and dolomite.

Although a trained geologist can identify rock type from observation, it is clear that cross-correlation between data from different instruments, both observational and analytical, is essential to fully characterise unknown rock types, as demonstrated by this study. The iterative approach documented here, refining initial observational and analytical interpretations through comparison with data obtained by other methods, demonstrates the force of this interactive process and the complementarity of the ExoMars geological instrument suite.

This study thus confirms the ability of the ExoMars geological instruments to carry out high quality analyses. The panoramic (field camera) and smaller-scale (CLUPI) images of the geological context provided by the cameras and the mineralogical information obtained with the RLS, Ma_Miss and MicrOmega instruments are each necessary and suitably complementary. The trained geologists were able to determine rock type from the variety of details obtained from orbit and from the field/hand specimen images. This preliminary identification was very helpful for interpreting the spectral data. The cross-calibrated spectral data were essential for the subsequent mineralogical interpretation (Table 2), in particular for determining the presence of water-bearing mineral species, important for understanding deposition/weathering/alteration signatures that have a bearing on microbial-scale habitability and the potential for preserving past traces of life.

These results allow a number of important conclusions to be drawn for future Mars and general planetary in situ missions:

1. Cross-correlation of data obtained with a complementary suite of observational and analytical instruments, evaluated by trained geologists is essential for the full characterisation of the rocks.

2. While the use of pure minerals for space instrument calibration is useful during the development phase of the instruments, preparation for an in situ mission using a suite of complementary instruments requires cross-testing with suitable analogue rocks exhibiting heterogeneous structures, textures, and mineralogy.

3. Interpretation of the data is best made by the multidisciplinary mission team, including geologists, spectroscopists, geochemists, and engineers (evaluation of the microbial-scale habitability and eventual biosignatures needs also to include relevant expertise).

Table 1

Summary table of interpreted results after the Blind Test exercise, compared to sample characteristics in the ISAR data base.

\begin{tabular}{|c|c|c|c|c|c|c|c|}
\hline \multirow[t]{2}{*}{ Samples } & \multicolumn{6}{|l|}{ Blind Test operations } & \multirow{2}{*}{$\begin{array}{l}\text { ISAR } \\
\text { Mineralogy optical } \\
\text { microscope, IR, Raman, } \\
\text { XRD, and Mössbauer } \\
\text { (details in Bost et al., 2013) }\end{array}$} \\
\hline & Satellite & Outcrop & Optical & Raman & IR-Ma_Miss & $\begin{array}{l}\text { IR- } \\
\text { MicrOmega }\end{array}$ & \\
\hline A & $\begin{array}{l}\text { Sedimentary } \\
\text { environment; } \\
\text { vertical structure of } \\
\text { tectonic origin }\end{array}$ & $\begin{array}{l}\text { Sedimentary } \\
\text { rock, mainly } \\
\text { quartz }\end{array}$ & $\begin{array}{l}\text { Sedimentary layering } \\
\text { (compositional, size) } \\
\text { mainly quartz, poss.organic } \\
\text { matter- rich (?). }\end{array}$ & $\begin{array}{l}\text { quartz, muscovite, } \\
\text { anatase, calcite } \\
\text { and carbonaceous } \\
\text { matter }\end{array}$ & $\begin{array}{l}\text { Layering -sedimentary rock } \\
\mathrm{Fe}^{2+} \text { (silicates or Fe- } \\
\text { sulphides), sedimentary } \\
\text { layers, OH-metal }\end{array}$ & $\begin{array}{l}\text { kaolinite } \\
\text { (muscovite) }\end{array}$ & $\begin{array}{l}\text { quartz, anatase, muscovite, } \\
\text { goethite, rutile, and } \\
\text { kerogen }\end{array}$ \\
\hline B & $\begin{array}{l}\text { Fe-rich } \\
\text { environment, along } \\
\text { a river, possible } \\
\text { volcanic }\end{array}$ & $\begin{array}{l}\text { Altered } \\
\text { volcanic rocks } \\
\text { with spinifex } \\
\text { textures }\end{array}$ & $\begin{array}{l}\text { Volcanic rocks with olivine } \\
\text { spinifex textures }\end{array}$ & $\begin{array}{l}\text { Magnetite, talc } \\
\text { and clays }\end{array}$ & $\begin{array}{l}\text { Antigorite (serpentine } \\
\text { group), iron oxides, basaltic } \\
\text { glass }\end{array}$ & $\begin{array}{l}\text { Olivine, } \\
\text { saponite, } \\
\text { antigorite }\end{array}$ & $\begin{array}{l}\text { Olivine, antigorite, } \\
\text { phlogopite, dolomite, } \\
\text { haematite, magnetite } \\
\text { (+talc) }\end{array}$ \\
\hline
\end{tabular}


Table 2

A protocol for reliable geological study (observation/analytical strategy for reliable geological interpretation).

\begin{tabular}{|c|c|c|c|}
\hline Step & Main goal & Example of observations (goals) & Suggested instrument ${ }^{\mathrm{a}}$ : \\
\hline 1 & $\begin{array}{l}\text { Determination of large- } \\
\text { scale geological setting }\end{array}$ & $\begin{array}{l}\text { Rock exposure; large scale structure; presence of layered rocks; loose rock; } \\
\text { geomorphological evidence of water; mineralogical, } \mathrm{OH}^{-} \text {mapping; layering at depth }\end{array}$ & Orbital probe (e.g. IR,radar), cameras \\
\hline 2 & $\begin{array}{l}\text { Outcrop-scale geological } \\
\text { features }\end{array}$ & $\begin{array}{l}\text { General relationships: topography (related to lithologies, structures) Rock size, } \\
\text { nature (i.e. in situ or erratic block), large-scale structure (layering,dip, strike), } \\
\text { intrustions/veins, fractures, faults, jointing, } \\
\text { Lithofacies: rock types, facies associations, sequences etc., apparent rock } \\
\text { competence; stratigraphic relationships } \\
\text { Details: Cross-lamination, bedding, stratification, bedding thickness, geometry, } \\
\text { boundary style (e.g. sharp, gradual); sedimentary/volcanic structures; surface marks } \\
\text { e.g. ripples, desiccation cracks, evidence for palaeocurrents, sedimentary texture, } \\
\text { fabric; composition; evidence of weathering and secondary mineral formation; bulk } \\
\text { mineralogy, elemental composition; }\end{array}$ & $\begin{array}{l}\text { Panoramic, high resolution, spectral camera, } \\
\text { long range probe (e.g. LIBS) }\end{array}$ \\
\hline 3 & $\begin{array}{l}\text { Finer-scale observation/ } \\
\text { analysis compositional } \\
\text { data }\end{array}$ & $\begin{array}{l}\text { Fine-scale texture, structure of rock, e.g. style of laminae, grading, erosional structures, } \\
\text { water escape structures; bedding, vesicles, inclusions, concretions; fractures (filling, } \\
\text { orientation); Grains: distribution, size and shape (angularity, roundness), sorting; fine } \\
\text { (scale weathering texture), in situ compositional analysis (mineralogical, elemental) }\end{array}$ & $\begin{array}{l}\text { Panoramic and high resolution camera; } \\
\text { in situ probes e.g. APXS, LIBS, Raman, IR, } \\
\text { Mössbauer }\end{array}$ \\
\hline 4 & Mineral identification & $\begin{array}{l}\text { Major phases, e.g. olivine, pyroxenes, quartz, feldspar... } \\
\text { Minor phases, e.g. sulphates, oxides, chlorites... }\end{array}$ & $\begin{array}{l}\text { Microscope (basic geological knowledge) and } \\
\text { IR, Raman spectrometer, LIBs, XRD }\end{array}$ \\
\hline 5 & Gases identification & Recent organic matter (?) & GCMS \\
\hline 6 & Biosignatures & $\begin{array}{l}\text { Microstructures (e.g. coccids, layers, mineral alignment, ...) disseminated carbon } \\
\text { (carbonaceous materials specific arrangement, circles, layers...) }\end{array}$ & $\begin{array}{l}\text { Microscope (e.g. carbonaceous materials, } \\
\text { morphology,...), Raman and LD-GCMS }\end{array}$ \\
\hline 7 & Final conclusion & Habitability; biosignatures & Brain! - and perhaps sample return \\
\hline
\end{tabular}

${ }^{a}$ Instruments and technics are not detailed in this table. The non-geologist and interested reader is invited to consult general geological and mineralogical, manuals such as Deer et al. (2013).

\section{Acknowledgements}

We acknowledge the Centre National d'Etudes Spatiale (CNES), the CNRS and the Region Centre for funding. The ISAR collection is supported by the Observatoire des Sciences de l'Univers en région Centre (OSUC). The Ma_Miss instrument has been developed in Selex ES and funded by ASI. We acknowledge C. Pilorget and J.-P. Bibring for the "MicrOmega" measurements. We acknowledge B. Hofmann and M. Viso for constructive comments.

\section{References}

Bish, D.L. Blake, D.F, Vaniman, DT, Chipera, S.J. Morris, RV Ming D.W. Treiman, A.H, Sarrazin, P., Morrison, S.M., Downs, R.T., Achilles, C.N., Yen, A.S., Bristow, T.F., Crisp, J.A., Morookian, J.M., Farmer, J.D., Rampe, E.B., Stolper, E.M., Spanovich, N., MSL Science Team, 2013. X-ray diffraction results from mars science laboratory: mineralogy of rocknest at Gale crater. Science 341, 1238932-1-1238932-5.

Blake, D.F., Morris, R.V., Kocurek, G., Morrison, S.M., Downs, R.T., Bish, D., Ming, D.W., Edgett, K., Rubin, S, Goetz, D, Madsen, W., Sullivan, M.B., Gellert, R., Campbell, R. Treiman, I., McLennan, A.H. Yen, S.M., Grotzinger, A.S., Vaniman, J., Chipera, D.T., S.J., Achilles, C.N., Rampe, E.B., Sumner, D., Meslin, P.-Y., Maurice, S., Forni, O., Gasnault, O., Fisk, M., Schmidt, M., Mahaffy, P., Leshin, L.A., Glavin, D., Steele, A., Freissinet, C., Navarro-González, R., Yingst, R.A., Kah, L.C. Bridges, N., Lewis, K.W., Bristow, T.F., Farmer, J.D., Crisp, J.A., Stolper, E.M., Des Marais, D.J., Sarrazin, P., MSL Science Team, 2013. Curiosity at Gale crater, Mars: characterisation and analysis of the rocknest sand shadow. Science 341, 1239505-1-1239505-7.

Bost, N., Westall, F., Gaillard, F., Ramboz, C., Foucher, F., 2012. Synthesis of a spinifex-textured basalt as an analog to Gusev crater basalts, Mars. Meteorit. Planet. Sci. 45, 820-831.

Bost, N., Westall, F., Ramboz, C., Foucher, F., Pullan, D., Meunier, A., Petit, S., Fleischer, I., Klingelhöfer, G., Vago, J.L., 2013. Mission to Mars: characterisation of Mars analogue rocks for the International Space Analogue Rockstore (ISAR). Planet. Space Sci. 82-83, 113-127.

Burns, R.G., 1993. Mineralogical Applications to Crystal Field Theory. Cambridge University Press p. 576.

Chevrel, M.O., Baratoux, D., Hess, K., Dingwell, D., 2014. Viscous flow behavior of tholeiitic and alkaline Fe-rich martian basalts. Geochim. Cosmochim. Acta 124 $348-365$.

Clark, R.N., King, T.V.V., Klejwa, M., Swayze, G.A., Vergo, N., 1990. High Spectral Resolution Reflectance Spectroscopy of Minerals. J. Geophys. Res. 95, $12,653-12,680$.

Coradini, A., Piccioni, G., Amici, S., Bianchi, R., Capaccioni, F., Capria, M.T., De Sanctis, M.C., Di Lellis, A.M., Espinasse, S., Federico, C., Fonti, S., Arnold, G., Atreya, S.K., Owen, T., Blecka, M., Bini, A., Cosi, M., Pieri, S., Tacconi, M., 2001. Mars multispectral imager for subsurface studies. Adv. Space Res. 28, 1203-1208.
Deer, W.A., Howie, R.A., Zussman, J., 2013. An Introduction to the Rock-Forming Minerals, 3rd ed. The Mineralogical Society p. 498.

de Vries, S.T., 2004. Early Archaean sedimentary basins: depositional environment and hydrothermal systems. Geol. Utraiectina 244, 1-160.

ESA, 2013. ExoMars Science Management Plan (draft). Doc. No.: EXM-MS-PL-ESA00002, Issue: 6, Rev. 0, 66 pp.

Foucher, F., Lopez-Reyes, G., Bost, N., Rull-Perez, F., Russmann, P., Westall, F., 2013. Effet of grain size distribution on Raman analyses and the consequence for in situ planetary missions. J. Raman Spectrosc. 44, 916-925.

Gaffey, S.J., 1985. Reflectance spectroscopy in the visible and near-infrared (0.35$2.55 \mu \mathrm{m})$ : applications in carbonate petrology. Geology 13, 270-273.

Hermosilla, I., Lopez-Reyes, G., Catala, A., Sanz, A., Llanos, D.R., Rull, F., 2012. Raman spectra processing algorithms and database for RLS-ExoMars. In: Proceedings of the European Planetary Science Congress, Madrid, France, September 23-28.

Hunt, G.R., 1977. Spectral signatures of particulate minerals in the visible and near infrared. Geophysics 42, 501-513.

Lopez-Reyes, G., Rull, F., Catala, A., Sanz, A., Medina, J., Hermosilla, I., Lafuente, B. 2012. A simple statistical method for the pseudo-quantification of mineral phases within the ExoMars Raman RLS instrument, abstract, GEORAMAN X Nancy, France, June 11-13, pp. 151-152.

Lopez-Reyes, G., Rull, F., Venegas, G., Westall, F., Foucher, F., Bost, N., Sanz, A. Catalá-Espí, A., Vegas, A., Hermosilla, I., Sansano, A., Medina, J., 2014. Analysis of the scientific capabilities of the ExoMars Raman Laser Spectrometer instrument. Eur. J. Mineral. 25, 721-733.

McSween, H.Y., Taylor, G.J., Wyatt, M.-B., 2009. Elemental composition of the Martian crust. Science 324, 736-739.

Nva-Mvondo, D., Martinez-Frias, J., 2007. Review komatiites: from Earth's geological settings to planetary and astrobiological contexts. Earth Moon Planets 100, 157-179.

Orberger, B., Rouchon, V., Westall, F., de Vries, S.T., Pinti, D.L., Wagner, C., Wirth, C., Hashizume, K., 2006. Microfacies and origin of some Archean chets. In: Reimold, W.U., Gibson, R.L. (Eds.), Processes on the Early Earth, vol. 405. Geological Society of America Special Paper, Pilbara, Australia, pp. 136-156.

Pilorget, C., 2012. Microscopie hyperspectrale dans le proche IR pour l'analyse in situ d'échantillons: l'instrument MicrOmega à bord des missions Phobos Grunt, Hayabusa-2 et ExoMars (Thesis). Université Paris Sud, Paris XI, 288 pp.

Pilorget, C., Bibring, J.-P., 2013. NIR reflectance hyperspectral microscopy for planetary science: Application to the MicrOmega instrument. Planet. Space Sci. 76, 42-52.

Rull, F., Maurice, S., Diaz, E., Tato, C., Pacros, A. and the RLS Team, 2011a. The Raman Laser Spectrometer (RLS) on the EXOMARS 2018 Rover Mission. In: Proceedings of the Lunar and Planetary Science Conference XXXXII, 2400 (abstract), March 7-11. The Woodland, Texas, USA.

Rull, F., Sansano, A., Díaz, E., Canora, C.P., Moral, A.G., Tato, C., Colombo, M. Belenguer, T., Fernández, M., Manfredi, J.A.R., Canchal, R., Dávila, B., Jiménez, A., Gallego, P., Ibarmia, S., Prieto, J.A.R., Santiago, A., Pla, J., Ramos, G., Díaz, C., González, C., 2011b. ExoMars Raman laser spectrometer for Exomars. In Proceedings of the Society of Photo-Optical Instrumentation Engineers (SPIE) Conference Series, 8152 (abstract).

Schwenzer, S.P., Kring, D.A., 2009. Impact-generated hydrothermal systems capable of forming phyllosilicates on Noachian Mars. Geology 37, 1091-1094. 
Westall, F., de Vries, S.T., Nijman, W., Rouchon, V., Orberger, B., Pearson, V., Watson, J., Verchovsky, A., Wright, I., Rouzaud, J.-N., Marchesini, D., Anne, S., 2006. The

3.466 Ga Kitty's Gap Chert, an Early Archaean microbial ecosystem. In: Reimold, W.U., Gibson, R. (Eds.), Processes on the Early Earth, vol. 405. Geological Society of America Special Publication, pp. 105-131.

Westall, F., Foucher, F., Cavalazzi, B., de Vries, S.T., Nijman, W., Pearson, V., Watson, J. Verchovsky, A., Wright, I., Rouzaud, J.-N., Marchesini, D., Anne, S., 2011.
Volcaniclastic habitats for early life on Earth and Mars: a case study from $\sim 3.5$ Ga-old rocks from the Pilbara, Australia. Planet. Space Sci., 59; , pp. 1093-1106. Westall, F., Loizeau, D., Foucher, F., Bost, N., Bertrand, M., Vago, J.L., Kminek, G., Zegers, T., 2013. Scenarios for the search for life on a habitable Mars. Astrobiology 13, 887-897. 